\title{
OS EFEITOS DO MÉTODO PILATES NA FUNCIONALIDADE DO ASSOALHO PÉLVICO FEMININO E NA INCONTINÊNCIA URINÁRIA: UMA REVISÃO SISTEMÁTICA
}

\author{
THE EFFECT OF PILATES METHOD IN THE FUNCTIONALITY OF FEMALE PELVIC FLOOR \\ AND IN URINARY INCONTINENCE: A SYSTEMATIC REVIEW
}

\author{
Ana Paula Jardim Pires do Couto ${ }^{\mathrm{a}^{*}}$ \\ Orcid: https://orcid.org/0000-0001-9679-7664
}

\author{
Adriana Marques Toigo \\ Orcid: http://orcid.org/0000-0003-3405-064X
}

aninhajpires@gmail.com ${ }^{\mathrm{a}}$, adrytoigo@terra.com.br

Universidade La Salle, Canoas, Brasil

Data de Submissão :23/07/2019 Data de Aceite: 14/11/2019

\section{RESUMO}

Introdução: É a musculatura do assoalho pélvico (MAP) que sustenta a uretra e a bexiga, que se contrai durante o esforço de forma a prevenir a perda urinária. O enfraquecimento ou lesões nesta estrutura de suporte podem levar à sua disfuncionalidade. Segundo a Associação Internacional de Uroginecologia, a Incontinência Urinária (IU) é toda perda involuntária de urina. A IU pode ser classificada em 3 principais tipos: a Incontinência Urinária de Esforço (IUE), trata-se da perda involuntária de urina que ocorre durante a realização de atividades como tossir, espirrar, levantar pesos, rir ou exercitar-se, Incontinência Urinária de Urgência (IUU), caracteriza-se por um desejo súbito e abrupto de urinar, difícil de ser inibido e a Incontinência Mista (IUM) que é a IUE somada à IUU. Embora a MAP não tenha sido enfatizada no trabalho original do Método Pilates (MP), algumas escolas têm integrado o foco na MAP em sua abordagem. O objetivo deste estudo foi revisar achados anteriores quanto aos efeitos do MP na funcionalidade do assoalho pélvico feminino e na IU. Método: Foram selecionados e analisados artigos de periódicos arbitrados e estudos presentes em bancos de dados acadêmicos. Resultados: dez estudos foram selecionados para análise dos resultados. Os estudos abordaram o efeito do MP na funcionalidade do assoalho pélvico feminino e na IU. Conclusão: Observou-se que o MP trouxe resultados positivos na maioria das variáveis analisadas em 9 dos 10 estudos selecionados, porém mais estudos são necessários.

Palavras-chave: Método Pilates; assoalho pélvico; incontinência urinária

\section{ABSTRACT}

Introduction: The pelvic floor muscles supports the urethra and bladder, which contracts during exertion to prevent urinary loss. Weakening or injury to this support structure may lead to dysfunction. According to the International Association of Urogynecology, urinary incontinence is any involuntary loss of urine. Urinary incontinence can be classified into 3 main types: stress urinary incontinence (involuntary loss of urine that occurs while performing coughing, sneezing, weight lifting, laughing or exercising), urgent urinary incontinence (characterized by a sudden and abrupt urge to urinate, which is difficult to inhibit) and mixed incontinence (a combination among stress and urgent urinary incontinences). Although pelvic floor muscles has not been emphasized in the original work of the Pilates Method, some schools have integrated the focus on these muscles into their approach. The aim of this study was to review previous findings regarding the effects of the Pilates Method on female pelvic floor functionality and urinary incontinence. Method: papers from refereed journals and studies in academic databases were selected and analyzed. Results: Ten studies were selected for analysis of the results. The studies addressed the effect of Pilates Method on female pelvic floor functionality and urinary incontinence. Conclusion: It was observed that Pilates Method had positive results in most of the variables analyzed in 9 out of 10 selected studies, but more studies are needed.

Keywords: Pilates method; pelvic floor; urinary incontinence 


\section{INTRODUÇÃO}

O assoalho pélvico (AP) é formado pelos músculos do diafragma pélvico e diafragma urogenital. Ele se estende entre o púbis anteriormente e o cóccix posteriormente e vai de uma parede lateral da pelve até a outra ${ }^{(1)}$. O diafragma pélvico é formado pelos músculos coccígeo e levantador do ânus, que se dividem em pubococcígeo, puborretal e ileococcígeo. O diafragma urogenital é uma estrutura músculo-fascial, composta pelos músculos bulboesponjoso, transverso superficial do períneo e isquiocavernosos ${ }^{(2)}$. A estrutura do AP é constituída de fibras musculares do tipo I, que são fibras de contração lenta (compõem $70 \%$ do $\mathrm{AP}$ ), resistentes à fadiga muscular, responsáveis pelo tônus, e de fibras do tipo II, que são fibras de contração rápida e vigorosa, produzem maior força e potência, porém são fadigáveis. Os músculos do AP (MAP) são responsáveis, quando se contraem, por manter a continência urinária e fecal, e quando se relaxam, por permitir o esvaziamento intestinal e vesical; evitam o deslocamento dos órgãos pélvicos (prolapso) e atuam durante o ato sexual. Nas mulheres, os MAP são extremamente distendidos para permitir o parto, mas devem contrair durante o pós-parto para permitir a continuidade de suas funções ${ }^{(3)}$. Na mulher adulta, esta região contém uma proporção maior de fáscia em relação a músculo e por isso, quando rompida em decorrência do parto pode nunca mais ter a força requerida para manter os órgãos genitais dentro da cavidade intra-abdominal ${ }^{(3)}$.

Segundo a Associação Internacional de Uroginecologia $^{(4)}$, a Incontinência Urinária (IU) é toda perda involuntária de urina. A IU pode ser classificada em 3 principais tipos: a Incontinência Urinária de Esforço (IUE), na qual a perda involuntária de urina que ocorre durante a realização atividades como tossir, espirrar, levantar pesos, rir ou exercitar-se, a Incontinência Urinária de Urgência (IUU), caracterizada por um desejo súbito e abrupto de urinar, difícil de ser inibido e a Incontinência Mista (IUM) que é a IUE somada a $\mathrm{IU}^{(5)}$. Além destas, há também a Incontinência Anal (IA), que consiste na ação que engloba a perda involuntária tanto de fezes quanto de gases, sendo caracterizada pela incapacidade de manter o controle fisiológico do conteúdo fecal em local e tempo adequados. A ocorrência simultânea de IA e IUU é caracterizada como IUD ${ }^{(6)}$.

Apesar da menor prevalência da IA quando comparada a IU, as duas exercem um grande impacto sobre a saúde e qualidade de vida dos indivíduos que as possuem. A IUE ocorre em pelo menos $10-20 \%$ das mulheres e muitas não sabem que há tratamentos simples e eficazes disponíveis ${ }^{(4)}$. São considerados como fatores de risco para a IUE o parto (especialmente o realizado via vaginal), partos múltiplos e trabalhos de parto demorados que podem levar a traumas significativos nas estruturas do AP.

Outros fatores etiológicos relacionados são constipação crônica, esforços exagerados, tabagismo, tosse crônica, obesidade, histerectomia e alterações hormonais ${ }^{(7)}$.

Viktrup et al. ${ }^{(8)}$ constataram que a prevalência da IUE aumentava em cerca de $7 \%$ aos três meses pós-parto para 30 e $42 \%$ aos cinco e aos 12 anos após o parto, respectivamente, e que as mulheres que apresentam IUE três meses após o seu primeiro parto têm um risco muito elevado (92\%) de persistência dos seus sintomas cinco anos mais tarde. A incontinência urinária pós-natal pode não ser, portanto, um estado passageiro, mas uma problemática que merece atenção particular.

A hipotonia (redução ou perda do tônus muscular) da MAP, também pode ser um fator agravante. Atividades físicas de alto impacto também podem estar relacionadas à perda involuntária de urina ${ }^{(9)}$. Com relação à prática de exercício físico, a IUE é a disfunção mais documentada do assoalho pélvico e acomete principalmente atletas que praticam atividades consideradas de alto impacto, como trampolim e paraquedismo, podendo levar ao enfraquecimento da MAP. Para prevenir a IU decorrente das atividades físicas é necessário que os profissionais orientem a mulher quanto aos possíveis acometimentos e à importância do fortalecimento perineal, porém, existe pouco conhecimento acerca do funcionamento dos músculos do períneo durante a prática de atividades físicas e esportivas $^{(10)}$.

Em mulheres jovens, nulíparas e não atletas tem-se verificado elevada taxa de queixa de perda urinária, independente se sejam ou não 
praticantes de atividade física ${ }^{(11)}$. O motivo para esse aumento na taxa de prevalência ainda não está bem definido uma vez que mulheres jovens e nulíparas dificilmente terão lesões de ligamentos, de fáscias em decorrência de compromisso de tecido conjuntivo, lesão de fibras musculares e de nervos do AP ocasionados por partos e gestações. Contudo, acredita-se que um dos motivos seja a fraqueza, de ordem hereditária, do tecido conjuntivo, com localização mais baixa do AP e fraqueza da MAP em atributo do próprio desuso desta musculatura ${ }^{(11)}$.

Desse modo, faz-se necessária a busca por uma prática de atividade física que, além de contemplar o desenvolvimento da aptidão, coordenação motora e demais fatores intrínsecos à tarefa, contribua para a melhora do funcionamento do assoalho pélvico feminino e, consequentemente, diminua ou reverta o quadro de incontinência urinária. Uma possível alternativa é o Método Pilates.

Joseph H. Pilates (1880-1967) criou um método de atividade física que combina arte e ciência. $\mathrm{O}$ método em questão, originalmente chamado de "contrologia" por seu criador, mas hoje conhecido por seu sobrenome - "Pilates" - distingue-se por trabalhar de forma intensa a musculatura abdominal, enquanto procura alongar e fortalecer as outras partes do corpo por meio de exercícios de baixo impacto e com poucas repetições ${ }^{(12)}$. É um programa de treinamento físico e mental que considera o corpo e a mente como uma unidade, dedicando-se a explorar o potencial de mudança do corpo humano. Esta mudança, que tem como meta alcançar um melhor condicionamento do corpo, baseia-se no fortalecimento do centro de força, expressão que denomina a circunferência do tronco inferior, que é considerada como a estrutura que suporta e reforça o resto do corpo ${ }^{(13)}$.

A transformação dos exercícios criados por Joseph Pilates se tornou mais acentuada com sua expansão, passou a sofrer mais ainda a influência de diversos campos, e diversas práticas somáticas, mostrando clara tendência à individualização de novas abordagens e à introdução de novos princípios, se ampliou o conceito de "casa de força" ou "powerhouse" que além da musculatura abdominal e lombar, hoje tende a incorporar o diafragma, o assoalho pélvico e a musculatura adutora e abdutora do quadril ${ }^{(12)}$. Muscolino e Cipriani ${ }^{(14)}$ descrevem detalhadamente este conceito no estudo "Pilates and the powerhouse I".

A atividade sinérgica entre a MAP e os músculos abdominais possibilita o desenvolvimento de uma pressão de fechamento adequada e importante para manter a continência urinária e fecal de forma coordenada a fim de aumentar a pressão no abdômen e fornecer suporte para os órgãos pélvicos ${ }^{(15)}$.

Embora a MAP não tenha sido especificamente enfatizada no trabalho original de Joseph Pilates, algumas escolas têm integrado os focos nesta região em suas abordagens. No trabalho do Pilates original, a MAP é comumente abordada de modo menos formal ao encorajar homens e mulheres a tracionarem os músculos desta região para dentro e para cima, enquanto ativam o músculo transverso do abdômen antes e durante a realização de muitos exercícios ${ }^{(16)}$. Porém, a errada contração da MAP e do transverso do abdômen podem resultar na contração da musculatura superficial e protrusão abdominal, favorecendo o aparecimento da incontinência urinária ${ }^{15}$.

Sendo assim, faz-se necessário que os profissionais da área do movimento, especialmente os profissionais de Educação Física, tenham o conhecimento da importância da funcionalidade da MAP, e saibam como trabalhar na prevenção da IU e na manutenção da musculatura desta região. Portanto, o objetivo deste estudo foi revisar achados anteriores quanto aos efeitos do Método Pilates na melhora da funcionalidade do assoalho pélvico feminino e na IU.

\section{MÉTODO}

O presente estudo foi realizado como uma revisão sistemática de literatura, a partir da busca em livros e de estudos anteriores em bases de dados como US National Library of Medicine (PubMed), Scientific Eletronic Library Online (SCiELO), EBSCO e Google Acadêmico. Foram selecionados artigos publicados nos últimos 10 anos até 2018, e incluídos estudos publicados nas línguas portuguesa e inglesa. Os descritores utilizados foram: Método Pilates, assoalho pélvico, incontinência urinária, method pilates, pelvic floor 
e urinary incontinence. O cruzamento dos termos supramencionados, por via do operador booleano and também foi efetuado.

A intersecção utilizada para os descritores está diagramada no Quadro 1.

Quadro 1- Resultado da busca dos dados

\begin{tabular}{|l|l|l|}
\hline \multicolumn{2}{|l|}{ - Pilates } \\
\hline $2-$ Assoalho Pélvico \\
\hline $3-$ Incontinência Urinária \\
\hline SCIELO & PUBMED & EBSCO \\
\hline $1-85$ & $1-392$ & $1-1395$ \\
\hline $2-353$ & $2-6465$ & $2-108$ \\
\hline $3-1090$ & $3-16089$ & $3-192$ \\
\hline 1 and $2-2$ & 1 and $2-17$ & 1 and $2-336$ \\
\hline 1 and $3-0$ & 1 and $3-5$ & 1 and $3-2$ \\
\hline
\end{tabular}

Fonte: Autoria própria, 2019.
Como critérios de inclusão, foram considerados artigos publicados entre 2008 e 2018 que trouxessem evidências científicas sobre os efeitos de uma intervenção com Método Pilates na funcionalidade do assoalho pélvico feminino. Os critérios de exclusão foram pesquisas provenientes de estudos com indivíduos do sexo masculino, crianças, gestantes, mulheres atletas, artigos de revisão, teses e dissertações.

Ao final da busca, foram selecionados 10 artigos publicados entre 2008 a 2018. O organograma apresentado na Figura 1 elucida os estudos selecionados:

Figura 1 - Organograma dos artigos selecionados

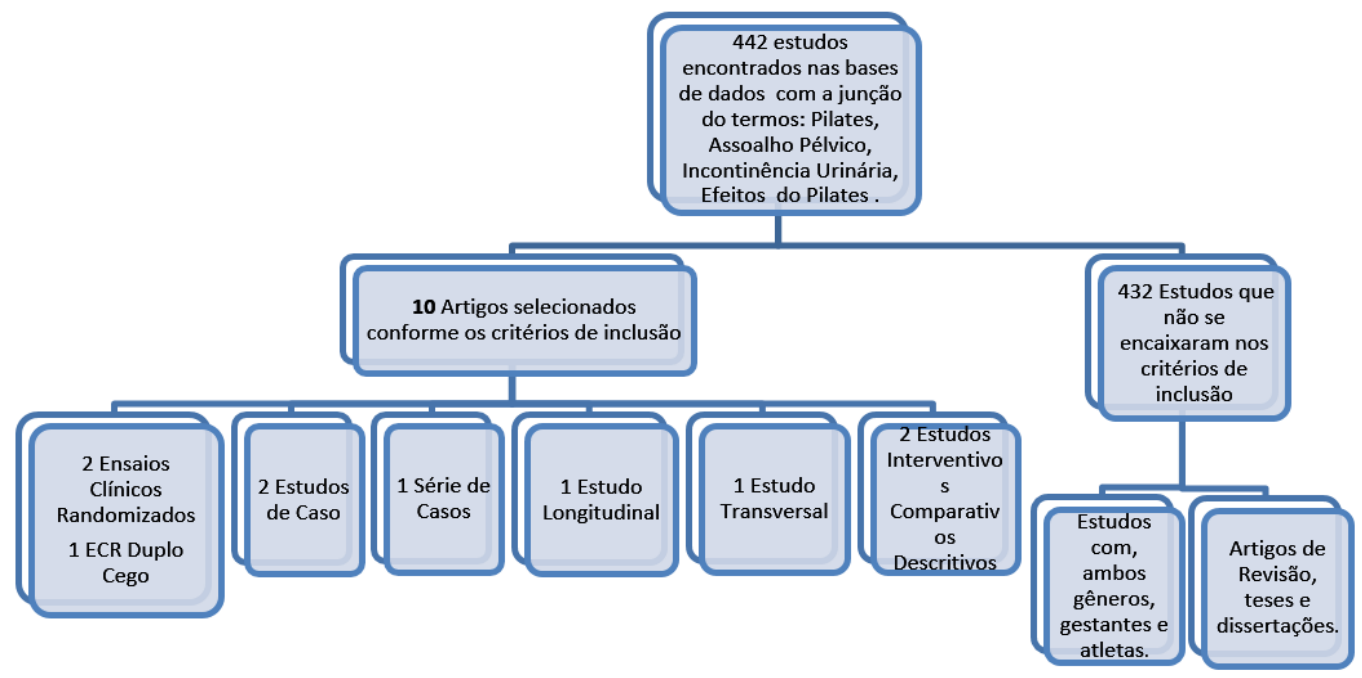

Fonte: Autoria própria, 2019.

\section{RESULTADOS E DISCUSSÃO}

O presente estudo teve como objetivo verificar, por meio de uma revisão de literatura, os Efeitos do Método Pilates na funcionalidade do assoalho pélvico feminino e na IU. O quadro 2 apresenta os detalhes de cada estudo e segue a ordem cronológica de publicação. 
Quadro 2 - Estudos em ordem cronológica

\begin{tabular}{|c|c|c|c|c|c|}
\hline \multirow{2}{*}{ Autor } & \multirow{2}{*}{$\begin{array}{l}\text { Desenho do Es- } \\
\text { tudo }\end{array}$} & \multirow{2}{*}{ Amostra } & \multicolumn{2}{|c|}{ Intervenção } & \multirow{2}{*}{ Resultados } \\
\hline & & & Variáveis & Protocolo & \\
\hline $\begin{array}{l}\text { ANDREAZZA } \\
\text { e SERRA } \\
(2008)\end{array}$ & $\begin{array}{l}\text { Pesquisa } \\
\text { de campo, } \\
\text { comparativa, } \\
\text { qualiquantitativo- } \\
\text { descritiva }\end{array}$ & $\begin{array}{l}12 \text { mulheres, } \\
\text { com idades de } \\
36 \text { a } 57 \text { anos, que } \\
\text { já tivessem tido } \\
\text { pelo menos uma } \\
\text { gestação, sem } \\
\text { disfunções no } \\
\text { assoalho pélvico, } \\
\text { sem cirurgia } \\
\text { perineal e não } \\
\text { atletas }\end{array}$ & $\begin{array}{c}\text { Grau de força } \\
\text { muscular das fibras } \\
\text { tipo I e II, e tempo de } \\
\text { sustentação }\end{array}$ & $\begin{array}{l}\text { Grupo 1: } \\
\text { Praticantes de } \\
\text { Pilates há mais de } 6 \\
\text { meses ( } \mathrm{n}=4 \text { ) } \\
\text { Grupo 2: Não } \\
\text { praticantes de } \\
\text { nenhum exercício } \\
\text { há no mínimo } 6 \\
\text { meses ( } \mathrm{n}=4 \text { ) } \\
\text { Grupov3: } \\
\text { Praticantes } \\
\text { de alguma } \\
\text { modalidade, exceto } \\
\text { Pilates ( } \mathrm{n}=4 \text { ) } \\
\\
\text { Única medição } \\
\text { para cada variável, } \\
\text { com biofeedback } \\
\text { perineal }\end{array}$ & $\begin{array}{l}\text { Maior média de força } \\
\text { muscular das fibras tipo } \\
\text { I nos grupos } 1 \text { e } 2 \\
\text { Maior média de força } \\
\text { muscular das fibras tipo } \\
\text { II no grupo } 1 \\
\text { Maior tempo de } \\
\text { sustentação no grupo } 3\end{array}$ \\
\hline $\begin{array}{l}\text { CULLIGAN et } \\
\text { al. (2010) }\end{array}$ & $\begin{array}{l}\text { Ensaio clínico } \\
\text { randomizado } \\
\text { Período }=12 \\
\text { semanas }\end{array}$ & $\begin{array}{l}52 \text { mulheres, } \\
\text { com idade igual } \\
\text { superior a } 18 \\
\text { anos, podendo ter } \\
\text { ou não, alguma } \\
\text { disfunção do } \\
\text { assoalho pélvico e } \\
\text { que não tivessem } \\
\text { experiência } \\
\text { prévia com } \\
\text { treinamento do } \\
\text { assoalho pélvico } \\
\text { formal ou Pilates }\end{array}$ & $\begin{array}{l}\text { Pressão e força } \\
\text { de contração do } \\
\text { assoalho pélvico }\end{array}$ & $\begin{array}{l}\text { Grupo Pilates ( } \mathrm{n}= \\
28) \\
\text { Grupo Treinamento } \\
\text { do assoalho pélvico } \\
\text { ( } \mathrm{n}=24) \\
2 \text { vezes por semana, } \\
\text { com duração de } 1 \\
\text { hora, cada grupo } \\
\text { (Mat Pilates e } \\
\text { Equipamentos) } \\
\text { Medição com } \\
\text { perineômetro pré e } \\
\text { pós intervenção }\end{array}$ & $\begin{array}{l}\text { Ambos os grupos } \\
\text { alcançaram aumento } \\
\text { significativo da } \\
\text { intensidade da } \\
\text { pressão da contração } \\
\text { voluntária máxima } \\
\text { após intervenção, mas } \\
\text { sem diferença entre os } \\
\text { grupos }\end{array}$ \\
\hline $\begin{array}{l}\text { DINIZ et al. } \\
(2014)\end{array}$ & 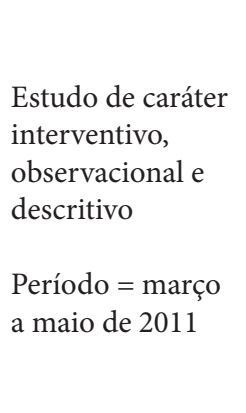 & $\begin{array}{l}6 \text { mulheres, de } \\
35 \text { a } 65 \text { anos, } \\
\text { podendo ter ou } \\
\text { não patologias } \\
\text { do AP, que não } \\
\text { realizassem } \\
\text { outro tipo de } \\
\text { atividade física } \\
\text { e não tivessem } \\
\text { em tratamento } \\
\text { uroginecológico }\end{array}$ & $\begin{array}{l}\text { Grau de força de } \\
\text { contração das fibras } \\
\text { tipo I e tipo II }\end{array}$ & $\begin{array}{l}\text { Sessões de Pilates } \\
\text { 2x por semana, } \\
\text { com } 60 \text { minutos de } \\
\text { duração cada (Mat } \\
\text { Pilates) } \\
\text { Avalição pré e } \\
\text { pós intervenção, } \\
\text { por meio do } \\
\text { perineômetro }\end{array}$ & $\begin{array}{l}\text { Todas as voluntárias } \\
\text { ganharam força } \\
\text { muscular nos dois tipos } \\
\text { de fibras, sendo que } 84 \% \\
\text { delas tiveram maior } \\
\text { ganho nas fibras do } \\
\text { tipo II }\end{array}$ \\
\hline
\end{tabular}




\begin{tabular}{|c|c|c|c|c|c|}
\hline \multirow{2}{*}{ Autor } & \multirow{2}{*}{$\begin{array}{l}\text { Desenho do Es- } \\
\text { tudo }\end{array}$} & \multirow{2}{*}{ Amostra } & \multicolumn{2}{|c|}{ Intervenção } & \multirow{2}{*}{ Resultados } \\
\hline & & & Variáveis & Protocolo & \\
\hline $\begin{array}{l}\text { FERLA et al. } \\
(2015)\end{array}$ & $\begin{array}{l}\begin{array}{l}\text { Estudo } \\
\text { observacional e } \\
\text { transversal }\end{array} \\
\text { Período = uma } \\
\text { única sessão para } \\
\text { as medições }\end{array}$ & $\begin{array}{l}60 \text { Mulheres com } \\
\text { idade e entre } \\
20 \text { e } 40 \text { anos; } \\
\text { índice de massa } \\
\text { corporal inferior } \\
\text { a 25; nulíparas; } \\
\text { sem nenhum } \\
\text { diagnóstico } \\
\text { clínico de } \\
\text { disfunções } \\
\text { do assoalho } \\
\text { pélvico e nunca } \\
\text { tiveram cirurgia } \\
\text { ginecológica }\end{array}$ & $\begin{array}{l}\text { Funcionalidade e } \\
\text { máxima contração } \\
\text { voluntária dos } \\
\text { músculos do } \\
\text { assoalho pélvico }\end{array}$ & $\begin{array}{l}\text { Grupo Pilates }(\mathrm{n}= \\
30) \\
\text { Grupo Sedentárias } \\
(\mathrm{n}=30) \\
\text { Medição feita em } \\
\text { uma única sessão }\end{array}$ & $\begin{array}{l}\text { Não houve diferença } \\
\text { estatisticamente } \\
\text { significativa entre os } \\
\text { grupos }\end{array}$ \\
\hline $\begin{array}{l}\text { PEREIRA et } \\
\text { al. (2016) }\end{array}$ & $\begin{array}{l}\text { Estudo de Caso } \\
\text { Período = } 14 \\
\text { semanas }\end{array}$ & $\begin{array}{l}\text { Uma mulher } \\
\text { com } 49 \text { anos, } \\
\text { obesa e diabética } \\
\text { com diagnóstico } \\
\text { clínico de } \\
\text { incontinência de } \\
\text { urgência dupla }\end{array}$ & $\begin{array}{l}\text { Força muscular do } \\
\text { assoalho pélvico, } \\
\text { frequência e } \\
\text { quantidade da perda } \\
\text { do conteúdo urinário } \\
\text { e fecal, e qualidade } \\
\text { de vida }\end{array}$ & $\begin{array}{l}\text { Uma mulher com } \\
49 \text { anos de idade, } \\
\text { estatura de } 1,49 \mathrm{~m} \mathrm{e} \\
\text { massa corporal de } \\
99 \mathrm{~kg} \\
14 \text { sessões de } \\
60 \text { min cada, } 3 \\
\text { vezes por semana, } \\
\text { com protocolo de } \\
\text { vinte exercícios do } \\
\text { método Mat Pilates } \\
\text { Stop Test, } \\
\text { Questionário } \\
\text { Internacional de } \\
\text { Incontinência } \\
\text { Urinária e Îndice de } \\
\text { Incontinência Anal } \\
\text { de Jorge-Wexner }\end{array}$ & $\begin{array}{l}\text { Fortalecimento da } \\
\text { musculatura do assoalho } \\
\text { pélvico, redução da } \\
\text { frequência da perda do } \\
\text { conteúdo urinário e anal } \\
\text { e melhora da qualidade } \\
\text { de vida }\end{array}$ \\
\hline $\begin{array}{l}\text { BERTOLDI et } \\
\text { al. (2016) }\end{array}$ & Estudo de casos & $\begin{array}{l}2 \text { mulheres (1 e 2) } \\
\text { com idades entre } \\
40 \text { e } 55 \text { anos, } \\
\text { no período do } \\
\text { climatério, } \\
\text { que tivessem tido } \\
\text { pelo menos uma } \\
\text { gestação, não } \\
\text { praticassem o } \\
\text { método Pilates, } \\
\text { sem infecções no } \\
\text { trato urinário, } \\
\text { nulíparas, } \\
\text { histerectomizadas } \\
\text { ou que fizeram } \\
\text { perineoplastia }\end{array}$ & $\begin{array}{l}\text { Força de contração } \\
\text { da musculatura do } \\
\text { assoalho pélvico, e } \\
\text { qualidade de vida }\end{array}$ & $\begin{array}{l}(1)=50 \text { anos e (2) } \\
48 \text { anos } \\
10 \text { sessões de } 50 \\
\text { minutos, } 03 \text { vezes } \\
\text { por semana } \\
\text { Avaliação visual } \\
\text { funcional, teste dos } \\
\text { cones vaginais, teste } \\
\text { de fibras do tipo I } \\
\text { e tipo II por meio } \\
\text { do perineômetro } \\
\text { e Women's Health } \\
\text { Questionnaire }\end{array}$ & $\begin{array}{l}\text { Aumento da força de } \\
\text { contração } \\
\text { da MAP nas duas } \\
\text { voluntárias com } \\
\text { discreta influência na } \\
\text { autopercepção da } \\
\text { qualidade de vida }\end{array}$ \\
\hline
\end{tabular}




\begin{tabular}{|c|c|c|c|c|c|}
\hline \multirow{2}{*}{ Autor } & \multirow{2}{*}{$\begin{array}{c}\text { Desenho do Es- } \\
\text { tudo }\end{array}$} & \multirow{2}{*}{ Amostra } & \multicolumn{2}{|c|}{ Intervenção } & \multirow{2}{*}{ Resultados } \\
\hline & & & Variáveis & Protocolo & \\
\hline $\begin{array}{l}\text { MUNIZ } \\
\text { et al (2016) }\end{array}$ & $\begin{array}{l}\text { Estudo } \\
\text { Longitudinal } \\
\text { Período = } 12 \\
\text { semanas }\end{array}$ & $\begin{array}{l}10 \text { mulheres com } \\
\text { mais de } 60 \text { anos } \\
\text { de idade, ativas } \\
\text { sexualmente, não } \\
\text { tabagistas, não } \\
\text { etilistas, } \\
\text { sem diagnóstico } \\
\text { clínico de } \\
\text { disfunção do } \\
\text { assoalho pélvico, } \\
\text { sem histórico de } \\
\text { infecção do trato } \\
\text { urinário, } \\
\text { sem história } \\
\text { de cirurgia } \\
\text { ginecológica } \\
\text { prévia recente } \\
\text { (há menos de } 5 \\
\text { anos) }\end{array}$ & $\begin{array}{l}\text { Pressão e } \\
\text { contratilidade da } \\
\text { musculatura do } \\
\text { assoalho pélvico }\end{array}$ & $\begin{array}{l}\text { Grupo único } \\
\text { Total de } 24 \text { sessões } \\
\text { do Método Pilates, } \\
\text { 2x por semana, } \\
\text { com } 60 \text { minutos de } \\
\text { duração cada sessão } \\
\text { (Mat Pilates) } \\
\\
\text { A pressão da } \\
\text { Musculatura do } \\
\text { assoalho pélvico } \\
\text { foi avaliada por um } \\
\text { perineômetro } \\
\text { e a contratilidade } \\
\text { pelo esquema } \\
\text { PERFECT, antes e } \\
\text { após intervenção. }\end{array}$ & $\begin{array}{l}\text { Aumento da pressão, } \\
\text { aumento da resistência } \\
\text { e aumento do número } \\
\text { de contrações rápidas da } \\
\text { musculatura do assoalho } \\
\text { pélvico }\end{array}$ \\
\hline $\begin{array}{l}\text { TORELLI } \\
\text { et al (2016) }\end{array}$ & $\begin{array}{l}\text { Ensaio clínico } \\
\text { randomizado } \\
\text { duplo cego } \\
\text { Período = } 24 \\
\text { sessões }\end{array}$ & $\begin{array}{l}48 \text { mulheres } \\
\text { saudáveis } \\
\text { (sem doença } \\
\text { ginecológica/ } \\
\text { neurológica), } \\
\text { sedentárias } \\
\text { nulíparas, } \\
\text { de idade } \\
\text { reprodutiva, } \\
\text { sem histórico } \\
\text { de distúrbios } \\
\text { do AP e capaz } \\
\text { de realizar a } \\
\text { contração da } \\
\text { musculatura do } \\
\text { assoalho pélvico } \\
\text { corretamente }\end{array}$ & $\begin{array}{l}\text { Força, pico } \\
\text { de pressão e } \\
\text { pressão média da } \\
\text { musculatura do } \\
\text { assoalho pélvico; } \\
\text { espessura músculo } \\
\text { pubovisceral e } \\
\text { área do hiato do } \\
\text { levantador }\end{array}$ & $\begin{array}{l}\text { Grupo Pilates } \\
\text { (n=24) e Grupo } \\
\text { Pilates + contração } \\
\text { da musculatura do } \\
\text { assoalho pélvico } \\
\text { (n=24). } \\
\text { 24 sessões do } \\
\text { Método Pilates, } \\
\text { com 1h de duração } \\
\text { cada sessão } \\
\text { (Mat Pilates e } \\
\text { equipamentos) } \\
\text { Pressão da } \\
\text { musculatura do } \\
\text { assoalho pélvico, } \\
\text { por meio do } \\
\text { perineômetro e } \\
\text { palpação vaginal, } \\
\text { e a espessura } \\
\text { da musculatura } \\
\text { perineal e área do } \\
\text { hiato levantador, } \\
\text { por meio de } \\
\text { ultrassonografia, } \\
\text { que foram medidas } \\
\text { na pré e pós- } \\
\text { intervenção. }\end{array}$ & $\begin{array}{l}\text { le } \\
\text { O Grupo Pilates } \\
\text { + contração da } \\
\text { musculatura do assoalho } \\
\text { pélvico demonstrou, } \\
\text { em relação ao Grupo } \\
\text { Pilates, melhora no pico } \\
\text { de pressão e pressão } \\
\text { média da musculatura } \\
\text { do assoalho pélvico, } \\
\text { aumento da espessura } \\
\text { na contração da } \\
\text { musculatura do assoalho } \\
\text { pélvico, mas sem } \\
\text { diferença em repouso. } \\
\text { Quanto à área hiato do } \\
\text { levantador em repouso, } \\
\text { não houve diferença, } \\
\text { tanto em repouso, } \\
\text { quanto em contração. }\end{array}$ \\
\hline
\end{tabular}


SCHRADER

et al (2017)
Ensaio clínico randomizado Período $=$ abril de 2014 a setembro de 2015
14 mulheres com queixa de perda urinária involuntária, com sintomas há pelo menos um ano, sem prolapsos de órgãos pélvicos graus

3 e 4 , classificados de acordo com o sistema Pelvic Organ Prolapse Quantification System, no período da menopausa

Intervenção Variáveis

\begin{tabular}{|c} 
Protocolo \\
\hline $\begin{array}{c}\text { Grupo } 1 \mathrm{com} \\
\text { biofeedback }(\mathrm{n}=7)\end{array}$
\end{tabular}

Grupo 2 tratadas pelo Método Pilates (Mat Pilates) $(\mathrm{n}=7)$

32 sessões com 2 etapas: $1^{\text {a }}(22, \mathrm{com}$ 2 atendimentos $\mathrm{p} /$ semana) e $2^{\mathrm{a}}$ (11 com 1 atendimento $\mathrm{p} /$ semana)

Média da frequência das perdas miccionais mensais, força de contração das fibras rápidas da musculatura do assoalho pélvico, duração da manutenção da contração das fibras lentas, gravidade da incontinência urinária e impacto desta sobre a qualidade de vida das participantes.
Questionário de

Incontinência

Urinária, Método

Pilates e biofeedback

Os atendimentos do Grupo 1 foram realizados com o perineômetro individualmente com exercícios específicos de contração da musculatura do assoalho pélvico

O G2 foi submetido a um protocolo de exercícios do Método Pilates solo.

As medidas das variáveis foram feitas antes da intervenção e ao término de cada
Ambas as técnicas foram eficazes no processo de hipertrofia muscular, refletindo em diminuição das perdas miccionais mensais e na melhora da qualidade de vida das participantes, porém somente o biofeedback apresentou eficácia sobre $o$ tempo de contração mantida etapa 


\begin{tabular}{|c|c|c|c|c|c|}
\hline \multirow{2}{*}{ Autor } & \multirow{2}{*}{$\begin{array}{l}\text { Desenho do Es- } \\
\text { tudo }\end{array}$} & \multirow{2}{*}{ Amostra } & \multicolumn{2}{|c|}{ Intervenção } & \multirow{2}{*}{ Resultados } \\
\hline & & & Variáveis & Protocolo & \\
\hline $\begin{array}{l}\text { COELHO } \\
\text { et al (2018) }\end{array}$ & Série de Casos & $\begin{array}{l}6 \text { mulheres com } \\
\text { incontinência } \\
\text { urinária de } \\
\text { esforço, com } \\
\text { idades entre } \\
35 \text { a } 80 \text { anos, } \\
\text { sem estarem } \\
\text { realizando } \\
\text { tratamento para } \\
\text { incontinência } \\
\text { urinária, sem } \\
\text { cirurgias } \\
\text { ginecológicas } \\
\text { recentes, sem } \\
\text { disfunção } \\
\text { uroginecológica } \\
\text { resultante de } \\
\text { lesão neurológica, } \\
\text { sem quadros } \\
\text { de infecção } \\
\text { uroginecológicas } \\
\text { e sem prolapsos } \\
\text { genitais }\end{array}$ & $\begin{array}{l}\text { Mensuração } \\
\text { da força da } \\
\text { musculatura do } \\
\text { assoalho pélvico e } \\
\text { quantificação da } \\
\text { perda urinária }\end{array}$ & $\begin{array}{l}1 \text { Grupo de } 6 \\
\text { mulheres com } \\
\text { in cont i n ê n c i a } \\
\text { urinária de esforço } \\
10 \text { sessões de } \\
\text { com duração } \\
\text { de } 40 \text { minutos, } \\
\text { de tratamento } \\
\text { utilizando o } \\
\text { Método Pilates } \\
\text { Avaliação funcional } \\
\text { dos músculos do } \\
\text { assoalho pélvico, } \\
\text { Pad Test e } \\
\text { pe ri n e ô me tro } \\
\text { e protocolo de } \\
\text { exercícios do } \\
\text { Método Pilates }\end{array}$ & $\begin{array}{l}\text { Todas as participantes } \\
\text { tiveram melhora } \\
\text { da força e resistência da } \\
\text { musculatura do } \\
\text { assoalho pélvico, com } \\
\text { média de melhora de } \\
29,8 \% \text {, redução de } 21,7 \% \\
\text { no } \\
\text { quadro de perda } \\
\text { urinária, aumento } \\
\text { da força muscular e } \\
\text { diminuição significativa } \\
\text { do quadro de } \\
\text { incontinência urinária } \\
\text { de esforço em } 66,6 \% \text { das } \\
\text { participantes e a cura de } \\
33,3 \%\end{array}$ \\
\hline
\end{tabular}

Fonte: Autoria própria, 2019.

Andreazza e Serra ${ }^{(17)}$, com objetivo de verificar se o método Pilates tem influência no fortalecimento dos músculos do assoalho pélvico, avaliaram 12 mulheres, de 35 a 49 anos, que foram divididas em três grupos com 4 voluntárias em cada, sendo o grupo I formado por mulheres que praticavam Pilates, o grupo II de mulheres sedentárias e grupo III de mulheres que praticavam outro tipo de exercício físico. As variáveis analisadas foram o grau de força muscular e o tempo de sustentação, mensurado com o aparelho de biofeedback (manômetro de pressão perineal com uma sonda introduzida no canal vaginal, que tem variação de graduação entre 0 a $12 \mathrm{~cm} \mathrm{Hg}$ ). A sonda era inflada com duas bombeadas suaves no manômetro de pressão e a seguir solicitava-se à voluntária a contração perineal pelo máximo de tempo que suportasse para, dessa forma, testar os dois tipos de fibras presentes no assoalho pélvico (fibras tipo I e fibras tipo II0, solicitadas quando há necessidade de uma contração rápida e forte. Todas as voluntárias atingiram o tempo mínimo de sustentação, não apresentando diminuição de força da MAP. Analisando o tempo de sustentação das fibras tipo I, o menor valor encontrado foi de 5s e o maior, 100s. Como a amostra era pequena, a análise dos dados ocorreu por média aritmética simples e os resultados referentes às médias do grau de força muscular das fibras do tipo I apontaram que as mulheres que praticavam o Método Pilates ou atividade física obtiveram maior força do que o grupo das mulheres que não praticava atividade física.

Culligan et al. ${ }^{(18)}$ analisaram se um Programa de Exercícios de Pilates (GP) e um Programa de Treinamento Muscular do Assoalho Pélvico (PTMAP) poderiam fornecer melhorias semelhantes na força muscular pélvica. Sessenta e duas mulheres foram inscritas e divididas em dois grupos: GP $(n=30)$ e PTMAP $(n=32)$. A principal variável analisada foi a força da MAP. Para a coleta dos dados os autores utilizaram um perineômetro e os questionários PDFI-20 (questionário com um total de 20 perguntas sobre o assoalho pélvico e seus sintomas) e PFIQ-7 (questionário complementar para o PFDI-20 que mede até que ponto os sintomas do assoalho pélvico afetam a qualidade de vida), os quais foram respondidos pelas participantes. Ambos os programas de exercícios consistiram de 24 sessões de 1 hora 
(duas vezes por semana, durante 12 semanas). No PTMAP os pesquisadores utilizaram um protocolo específico para PTMAP, biofeedback, manipulação vaginal, reeducação neuromuscular e terapia manual, para se concentrar estritamente na MAP. No GP, usando dicas verbais, os instrutores de Pilates ensinaram exercícios de corpo inteiro, enfatizando os "músculos centrais", especialmente a MAP. Em relação à força, tanto o GP quanto o grupo PTMAP, demonstraram melhora, mas sem diferença estatisticamente significativas entre os grupos. Os escores do questionário PFDI20 melhoraram em 48\% no GP, 53\% no grupo PTMAP pós a intervenção, mas também sem diferenças estatisticamente significativas entre os grupos. Os escores do PFIQ-7 melhoraram em $44 \%$ no GP e em 55\% no grupo PTMAP, com diferenças estatisticamente significativas entre os grupos. Concluíram o estudo 28 e 24 participantes no GP e PTMAP respectivamente. Sete das oito participantes que abandonaram o grupo PTMAP relataram achar o tratamento desagradável de alguma forma. Os autores observaram que, apesar de não haver diferença significativa entre os grupos, houve uma melhora em ambos após a intervenção. Para eles, os resultados do estudo podem servir para estimular a adesão a programas de exercícios baseados no Método Pilates para tratar e prevenir a disfunção da MAP. A razão para isto é a crença e que a participação no protocolo baseado no Método Pilates tenha sido mais aceitável do que o protocolo PTMAP por este último utilizar procedimentos invasivos, gerando, em algumas vezes, constrangimento e desconforto. Para os autores, é possível a prática do Pilates durante o período pós-parto ou pósoperatório ou como uma forma da reabilitação do assoalho pélvico após partos vaginais e/ou cirurgia reconstrutiva pélvica.

Diniz et al. ${ }^{(19),}$ com o objetivo de avaliar a força da MAP em mulheres praticantes do Método Pilates, analisaram uma amostra composta por seis mulheres com idades variando de 35 a 65 anos (média de 49,66 \pm 9,64 anos). A variável analisada foi o grau de força da MAP, por meio do perineômetro, observando qual tipo de fibra foi mais utilizada durante a prática desta atividade no solo (Mat Pilates). Na análise do grau de força, foi observado que as médias dos valores obtidos nas contrações das fibras do tipo I e II, antes e após a realização do Mat Pilates, apresentaram diferenças estatisticamente significativas $(\mathrm{p}<0,05)$ em $84 \%$ $(\mathrm{n}=5)$ das voluntárias. Ao comparar a média de ganho de força entre as fibras do tipo I e II $(7,16 \pm 1,53 \mathrm{mmHg}$ versus $10,90 \pm 2,5 \mathrm{mmHg}$, respectivamente), após a prática do Mat Pilates, observou-se um ganho maior nas fibras rápidas (tipo II) em $84 \%(n=5)$ das voluntárias, porém, essa diferença não foi estatisticamente significante $(\mathrm{p}>0,05)$. Após a análise dos resultados, os autores observaram que o Método Pilates influenciou na força de contração das fibras musculares do assoalho pélvico, podendo ser sugerido como forma de prevenção para o aparecimento ou tratamento das disfunções desta musculatura.

Ferla et al. ${ }^{(20)}$, com o objetivo de verificar se existe diferença na funcionalidade da MAP entre praticantes do Método Pilates e sendentárias, analisaram 60 mulheres de 20 a 40 anos que foram igualmente divididas em dois grupos: Praticantes do Método Pilates (GMP) e e sedentárias (GS). A variável analisada foi verificada pela pressão gerada durante as contrações voluntárias máximas (CVM) usando o perineômetro, e pela palpação vaginal, usando o esquema PERFECT $^{1}$ como referência, graduado pela letra $\mathbf{P}$. Além disso, um teste foi aplicado para verificar a correlação entre os resultados obtidos com o perineômetro (média $\mathrm{MVC}, \mathrm{cmH}_{2} \mathrm{O}$ ) e a palpação vaginal. Este estudo não utilizou nenhum protocolo de exercício específico, visto que a intenção era determinar se a prática de Pilates em diversas configurações, considerando um mínimo de 6 meses de prática, poderia alterar a funcionalidade da MAP. Depois de observar e registrar a intensidade da pressão

\footnotetext{
${ }^{1} \mathrm{O}$ esquema PERFECT é composto por sete itens e foi desenvolvido e validado para avaliar a funcionalidade da MAP. O "P" (power/ força) avalia a intensidade da contração voluntária máxima (CVM) da MAP, graduada segundo a escala de Oxford modificada. O "E" (endurance/resistência) avalia quanto tempo a CVM é mantida e sustentada em segundos, antes que haja uma perda de $35 \%$ ou mais da contração. O "R" (repetitions/repetições) avalia o número de repetições da contração sustentada (até 10) que a participante consegue realizar com duração satisfatória (5 segundos), com intervalo de 4 segundos entre cada contração. O "F" (fast/contrações rápidas) é avaliado após uma pequena pausa para repouso (1 minuto), verificando o número de CVM com duração de 1 segundo cada (até 10 contrações) ${ }^{(21)}$.
} 
de três repetições da CVM, a média dessas três medidas foi calculada. Os autores verificaram que não houve diferença estatisticamente significativa entre o grupo GMP e o GS em qualquer das variáveis analisadas e que mulheres saudáveis com idade entre 20 e 40 anos e nulíparas parecem não se beneficiar do método Pilates no que diz respeito à funcionalidade do AP, por acreditarem que nesta idade não há, ainda, perda de função ou alterações fisiológicas. A hipótese inicial de que a prática do método Pilates poderia melhorar a funcionalidade do AP e ser uma forma de exercício físico que fortaleceria esse grupo muscular, prevenindo sua disfunção, não foi confirmada neste estudo.

Pereira et al. ${ }^{(22)}$, com o objetivo de identificar a influência do método Pilates Solo na força da MAP na IUD, fizeram um estudo de caso com uma mulher de 49 anos, obesa, com IMC de 45,59 e diabética com diagnóstico clínico de IUD. As variáveis avaliadas foram a força muscular do assoalho pélvico, a frequência, a quantidade da perda do conteúdo urinário e fecal e qualidade de vida. Para a coleta de dados, os pesquisadores utilizaram o Stop Test ${ }^{2}$, o ICIQ-SF ${ }^{(23)}$ e o Índice de Incontinência Anal de Jorge-Wexner, atualmente denominado Índice de Incontinência Fecal da Cleveland Clinic Incontinence Score e conhecido na América Latina como Índice de Incontinência

Anal de Jorge-Wexner ${ }^{3}$. Na intervenção, os autores aplicaram um protocolo de vinte exercícios do método Pilates Solo, adaptados especificamente para o biótipo e condicionamento físico da participante. A participante foi submetida a um total 14 sessões com duração de 60 minutos, com uma frequência de 3 vezes semanais. Na avalição inicial, na escala do Stop Test, foi obtido grau 1, já na reavaliação (pós-intervenção), na mesma escala foi obtido grau 3. Na avaliação inicial (préintervenção) o ICIQ-SF foi aplicado e a paciente relatou perder urina com uma frequência de uma vez ao dia (3 pontos), uma moderada quantidade (4 pontos) que interferia de zero (não interfere) a dez (interfere muito) em sua qualidade de vida o número 7 , obtendo como somatória total das três questões principais 14 pontos. No entanto, durante a reavaliação (pós-intervenção) a paciente relatou perder conteúdo urinário duas ou três vezes por semana ( 2 pontos), uma pequena quantidade ( 2 pontos), interferindo de 0 (não interfere) a 10 (interfere muito) o número 4 , obtendo como somatória total 8 pontos, e no Índice de Incontinência Anal de Jorge-Wexner na avaliação inicial (pré-intervenção) a paciente relatou perder sólidos-ocasionalmente ( 2 pontos), líquidosfrequentemente ( 3 pontos), gases-ocasionalmente ( 2 pontos), uso de forro-nunca (0), tendo como alteração do estilo de vida-frequentemente (3 pontos), obtendo um total de 10 pontos, indicando uma incontinência anal moderada. Já na reavaliação, os seguintes resultados: sólidosnunca ( 0 pontos), líquidos-raramente ( 1 pontos), gases-nunca ( 0 pontos), uso de forro-nunca (0 pontos), tendo como alteração do estilo de vidanunca ( 1 pontos), obtendo uma somatória total de 2 pontos, indicando uma incontinência anal leve. Os autores observaram que o método Pilates Solo demonstrou influência positiva no fortalecimento da musculatura do assoalho pélvico, obtendo como efeitos a redução da frequência e da quantidade da perda do conteúdo urinário e anal, refletindo assim na melhora da qualidade de vida de uma mulher com IUD. Porém, os autores ressaltam que

${ }^{2}$ O Stop-test que consiste em um método de avaliação da força da musculatura do assoalho pélvico no qual é solicitada a interrupção do jato urinário por uma a duas vezes, após cinco segundos do início da micção. É classificado de acordo com o sucesso em interromper o jato e manter a interrupção pelo maior tempo possível em: grau 0 (não consegue interromper o jato); grau (interrompe o jato urinário, mas não consegue manter a interrupção; grau 2 (interrompe parcialmente o jato e o mantém por um curto intervalo de tempo); grau 3 (interrompe o jato urinário, mantendo a interrupção, porém com um tônus muscular fraco, tendo escape urinário); grau 4 (consegue interromper totalmente o jato, mantendo a interrupção com um bom tônus muscular) e grau 5 (interrompe totalmente o jato mantendo a interrupção com um tônus forte por um bom tempo) $)^{(3)}$.

${ }^{3} \mathrm{O}$ Índice de Incontinência Anal de Jorge-Wexner é composto por cinco variáveis. Cada uma recebe uma pontuação atribuída pelo paciente de forma objetiva, variando de zero a quatro pontos de acordo com a frequência em que ocorre o episódio de perda: zero (nunca); um (raramente ou $\leq 1 /$ mês); dois (ocasionalmente ou $\leq 1 /$ dia e $>1 /$ mês); três (frequentemente ou $\leq 1 /$ dia e $>1$ /semana) e quatro (sempre ou $>1$ /dia). As três primeiras variáveis referem-se ao tipo de incontinência fecal: para sólidos, líquido (ou muco) e gases (flatos). As duas últimas são sobre o uso de forro (protetor de vestimenta) e se ocorreu alteração no estilo de vida devido à incontinência fecal. A pontuação varia de 0 (continência fecal perfeita); 1-7 (incontinência fecal leve); 8-14 (incontinência fecal moderada) e 15-20 (incontinência fecal grave) ${ }^{(22)}$. 
estes resultados devem ser verificados com cautela e não generalizados por se tratar de estudo de caso com pouco tempo de intervenção.

Bertoldi et al. ${ }^{(24)}$ avaliaram a influência dos exercícios do Método Pilates na força de contração da MAP e na Qualidade de Vida (QV) de mulheres no climatério, com uma amostra composta por duas mulheres (1) e (2), com 50 e 48 anos respectivamente, sem disfunção da MAP. As variáveis analisadas foram a força de contração da MAP ea QV.A pré e pós-avaliação foram compostas pelos protocolos: anamnese, Questionário de Hauser ${ }^{4}$, Avaliação Visual Funcional (AFA) ${ }^{5}$, Teste dos Cones Vaginais (TCV $)^{6}$, teste de força com perineômetro para fibras rápidas (TPFR) e para fibras lentas (TPFL), e avaliação da QV com o Women's Health Questionnaire (WHQ) ${ }^{7}$. Esta avaliação foi realizada na pré-avaliação para verificação da presença dos sintomas climatéricos, pelo índice de Hauser: fenômenos vasomotores, palpitação cardíaca, insônia, depressão, irritabilidade, queixas urinárias, concentração e memória, diminuição da libido e secura vaginal. A intervenção consistiu em 10 sessões de 50 minutos, 03 vezes por semana, compostas por exercícios selecionados do método Pilates com o número de repetições baseado no método original. Os exercícios escolhidos englobavam mobilização, fortalecimento e alongamento, com ênfase no alinhamento e estabilização lombopélvica. Ao final da intervenção, as participantes 1 e 2 obtiveram no índice de HAUSER notas de 6,9 e 6,2 respectivamente, demonstrando a presença dos sintomas climatéricos. Em relação à prática de atividades físicas, a paciente 1 realizava caminhadas com frequência de 4 vezes na semana, enquanto a paciente 2 era sedentária. Nos testes AFA e TCV as participantes apresentaram grau 5 de força na pré-avaliação, permanecendo inalterados os graus na reavaliação. Os pesquisadores observaram contração consciente em ambas na avaliação inicial, porém com uso de músculos abdominais, o que não é o ideal. Já, ao final do tratamento a participante 1 apresentou a contração isolada da MAP. A força muscular do assoalho pélvico, verificada por meio da perineometria, apresentou melhora relevante. No TCFR, a participante 1 obteve ganho de força de $45,83 \%$ e a paciente 2 aumentou em $362,50 \%$. Na TCFL o aumento de força foi de $82,43 \%$ e $209,38 \%$ para as pacientes 1 e 2, respectivamente. Na avaliação da QV pelo WHQ, a participante 1 apresentou melhora nas dimensões: sintomas somáticos (14,29\%), sintomas vasomotores (12,5\%), ansiedade/temores $(12,5 \%)$, problemas de sono $(25 \%)$ e sintomas menstruais (12,5\%). A paciente 2 apresentou melhora somente nas dimensões: depressão $(10,72 \%)$, sintomas somáticos $(3,58 \%)$, sintomas

${ }^{4} \mathrm{O}$ questionário proposto por Hauser é constituído por uma tabela de sinais e sintomas, para a obtenção do índice, a paciente deve dar notas de 0 a 10 para cada um dos sintomas listados, sendo $0=$ ausência do sintoma e $10=$ sintoma muito exacerbado. Ao final, somam-se todas as notas e divide-se por 10. Considera-se elevado quando a paciente atinge a nota $7(24)$.

${ }^{5}$ AFA é um exame invasivo onde o fisioterapeuta realiza a palpação vaginal e solicita uma contração da musculatura do assoalho pélvico, como se fosse interromper o fluxo urinário e o avaliador observa a contração, baseando-se na sensibilidade da palpação digital é classificada em uma escala de 0 a 5: grau 0 (sem função perineal mesmo na palpação); grau 1 (contração reconhecida somente na palpação); grau 2 (função débil e contração reconhecida na palpação); grau 3 (função perineal presente e resistência colocada não é mantida por cinco segundos à palpação); grau 4 (função perineal presente e vence uma resistência mantida por cinco segundos por quatro repetições) e grau 5 (função perineal presente e vence uma resistência mantida por cinco segundos por cinco repetições)(24).

6 TCV é um teste que utiliza cones vaginais que são dispositivos de tamanhos iguais e pesos diferentes, que variam de $25 \mathrm{~g}$ a 65g. A avaliação funcional do AP realizada com estes dispositivos inicia-se com a paciente em posição ginecológica. Introduz-se na vagina o dispositivo mais leve, deixando-se o fio de nylon para fora e pede-se para a paciente vestir uma calcinha e caminhar durante um minuto, agachar, levantar e tossir quatro vezes. Caso o cone permaneça no canal vaginal, ele é removido e insere-se o próximo de maior peso e assim sucessivamente, até que algum deles se exteriorize durante os esforços. A classificação do grau de força do AP fez-se de acordo com o peso do cone sustentado no momento da avaliação: Índice TCV: (0) - o peso $\mathrm{n}^{\circ} 1$ (25g) cai; (1) - o peso no 1 é mantido e o $n^{\circ} 2$ (35g) cai; (2) - o peso $n^{\circ} 2$ é mantido e o $n^{\circ} 3$ (45g) cai; (3) - o peso $n^{\circ} 3$ é mantido e o $n^{\circ}$ 4 (55g) cai; (4) - o peso no 4 é mantido e o $\mathrm{n}^{\circ} 5$ (65g) cai; (5) - o peso no 5 é mantido(24).

7 Women's Health Questionnaire (WHQ) é um instrumento previamente validado para a língua portuguesa, sendo composto por 36 itens agrupados em nove domínios: sintomas somáticos, humor deprimido, dificuldades cognitivas, ansiedade, satisfação sexual, sintomas vasomotores, distúrbios do sono, atração e sintomas menstruais. Quanto maior o escore obtido, pior a qualidade de vida(25). 
menstruais (12,5\%), atratividade (8,34\%). Os autores observaram que no AFA e TCV, não havia déficit de força no pré-teste, mantendo os mesmos graus de força pós-tratamento e que a presente pesquisa apontou a evolução da força muscular dos sujeitos, considerando que os resultados foram positivos para ambas, porém mais significativos na paciente 2 , que era sedentária.

Muniz et al. ${ }^{(26)}$, com o objetivo de verificar a influência de um protocolo de exercícios do método Pilates na funcionalidade da MAP em mulheres idosas, submeteram dez voluntárias (média de idade de 63,4 $\pm 4,5$ anos) com pouca ou nenhuma disfunção do AP a 24 sessões de exercícios do método Pilates com duração de 1 hora, por 12 semanas. As variáveis analisadas foram a pressão da MAP por meio do perineômetro e a contratilidade da MAP por meio do esquema PERFECT. O protocolo de exercícios foi composto por 11 exercícios do Método Pilates. As sessões foram realizadas duas vezes por semana, com duração de 60 minutos cada. Os dados foram coletados antes e após a intervenção. Em razão da intervenção proposta, o grau de contração voluntária da MAP das participantes passou de $79,0 \pm 83,5$ para $90,0 \pm 82,0 \mathrm{cmH}_{2} \mathrm{O}$, com diferença estatisticamente significativa na comparação pareada $(p=0,012)$. No esquema PERFECT, houve aumento do tempo de sustentação das contrações

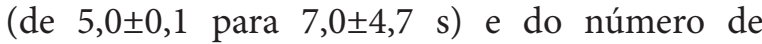
repetições rápidas (de $7,0 \pm 4,5$ para $8,0 \pm 4,7$ ), com diferença estatisticamente significativa para ambas as variáveis ( $p=0,017$ e $p=0,008$ respectivamente). Os autores observaram que o treinamento com os exercícios idealizados por Joseph Pilates aumentou a pressão, a resistência e o número de contrações rápidas dos músculos do assoalho pélvico e acreditam que os resultados do presente estudo podem eventualmente levar à ampliação do uso terapêutico do Métodos Pilates para tratar ou prevenir as disfunções do assoalho pélvico, principalmente, nos períodos em que esses músculos são mais exigidos, como na gestação, no pós-parto vaginal ou na terceira idade.

Torelli et al. ${ }^{(27)}$, com o objetivo de avaliar a eficácia da adição da contração da MAP (CMAP) a um Programa de Exercícios de Pilates (PEP), em um ensaio clínico randomizado duplo cego, analisaram uma amostra composta por 48 mulheres saudáveis (sem doença ginecológica/ neurológica), sedentárias, nulíparas, em idade reprodutiva, sem histórico de distúrbios do AP, e com idades entre 22 e 33 anos. As participantes foram igualmente divididas em gois grupos: PEP e PEP+CMAP. As variáveis analisadas foram a força, o pico de pressão e a pressão média da MAP (por meio do perineômetro e da palpação vaginal), e a espessura músculo pubovisceral (MP) e área do hiato do levantador (AHL) (por meio de ultrassonografia), que foram mensuradas na pré e pós-intervenção. $\mathrm{O}$ protocolo foi composto de 24 sessões do Método Pilates, com 60 minutos de duração por sessão. Na comparação das médias, houve diferenças estatisticamente significativas $(\mathrm{p}<0,05)$ nas variáveis pico de pressão $(\mathrm{cm}$ $\left.\mathrm{H}_{2} \mathrm{O}\right)$, pressão média $\left(\mathrm{cm} \mathrm{H}_{2} \mathrm{O}\right)$ e espessura $\mathrm{MP}$ na contração $(\mathrm{cm})$ tendo o grupo $\mathrm{PEP}+\mathrm{CMAP}$ apresentado melhoras significativas em relação ao grupo PEP. Os autores observaram que adicionar a execução da MAP durante os exercícios do Método Pilates mostrou-se mais eficaz do que somente o PEP sozinho.

Schrader et al. ${ }^{(28)}$, com o objetivo de verificar a eficácia do tratamento para incontinência urinária (do tipo IUM e IUE) com o método Pilates e o biofeedback manométrico em mulheres na menopausa, avaliaram 14 mulheres no período da menopausa, com média de idade de 55 $\pm 9,32$ anos, divididas em dois grupos. O grupo 1 (G1) foi submetido ao tratamento com o biofeedback e o grupo 2 com o Método Pilates (G2). Ambos realizaram trinta e duas sessões e foram avaliados antes e após os tratamentos considerados de curto (após vinte e duas sessões), médio (após trinta e duas sessões) e longo prazo (após dois meses sem intervenções). Em relação às variáveis analisadas, foram observadas a média da frequência das perdas miccionais mensais, a força de contração das fibras rápidas da MAP, a duração da manutenção da contração das fibras lentas, a gravidade da IU e o impacto desta sobre a QV das participantes, no pré e pós-tratamento em diferentes tempos (Pós 1, 2 e 3). Quanto ao tipo de IU, $12(85,71 \%)$ participantes apresentavam IUM e $2(14,29 \%)$ IUE, sendo que o G1 foi constituído por $5(71,42 \%)$ pacientes com sintomas de IUM e $2(28,58 \%)$ de IUE e o G2 por $7(100 \%)$ pacientes com IUM. Quanto à frequência das perdas 
miccionais mensais de cada participante, não foi observada diferença estatisticamente significativa entre os grupos. Quando comparados os resultados das quatro avaliações entre os grupos G1 e G2, observou-se que, em ambos, a média de frequência das perdas miccionais da primeira avaliação (pré) em relação à segunda apresentou redução estatisticamente significativa $(p=0,006$; $\mathrm{p}=0,003$, respectivamente). Após a terceira e quarta avaliações, foi observada estabilização do quadro, sem significância estatística entre estas últimas reavaliações $(\mathrm{p}>0,05)$. Foram também analisados os valores de contração rápida da MAP, não sendo observada diferença estatisticamente significativa entre os grupos $(p=0,968)$. Ao comparar os resultados das quatro avaliações intragrupo (G1 e G2 separadamente), observouse que, em ambos, a média de contrações rápidas da primeira avaliação em relação à segunda apresentou redução estatisticamente significativa $(\mathrm{p}=0,033 ; \mathrm{p}=0,013$, respectivamente). Após a terceira e quarta avaliações, foi novamente observada estabilização do quadro, com manutenção das médias de contração rápida, sem significância estatística entre estas últimas reavaliações $(\mathrm{p}>0,05)$. Em relação à duração das contrações mantidas, também não foi observada diferença estatisticamente significativa entre os grupos ( $\mathrm{F} 3,36=1,864 ; \mathrm{p}=0,153)$. Na comparação intragrupo (G1 e G2 separadamente), observouse que no $\mathrm{G} 1$ a média de contrações mantidas na primeira avaliação em relação à segunda apresentou aumento estatisticamente significativo $(\mathrm{p}=0,003)$, com manutenção elevada da média na terceira avaliação $(p=0,029)$, mas diminuição da média de contração na quarta avaliação $(\mathrm{p}=0,266)$. No G2, foi possível observar um aumento da média das contrações das fibras lentas entre os tempos de avaliação, porém sem diferença estatisticamente significativa entre nenhuma das avaliações $(p>0,05)$. Ambos os grupos apresentaram resultados estatisticamente significativos, quando realizada a comparação entre os grupos em relação à frequência das perdas urinárias mensais, força das fibras rápidas do assoalho pélvico, gravidade da incontinência urinária e o impacto desta sobre a QV das mulheres. Na duração das contrações mantidas, apenas o G1 apresentou diferenças significativas. Os autores perceberam que ambas as técnicas propostas para o tratamento da IU em mulheres na menopausa foram eficazes na redução da frequência das perdas miccionais mensais e no ganho de força muscular das fibras rápidas, com consequente aumento na $\mathrm{QV}$ em tratamentos a curto, médio e longo prazo. Porém somente o biofeedback apresentou eficácia sobre o tempo de contração mantida, sugerindo tratamento por meio deste método quando o objetivo for de melhorar essa variável.

Coelho et al. ${ }^{(29)}$, com o objetivo de verificar o efeito do Método Pilates na mensuração da força do MAP e na quantificação da perda urinária em mulheres com incontinência urinária de esforço, submeteram 6 indivíduos do sexo feminino com idade entre 35 a 80 anos a uma intervenção composta por avaliação funcional dos músculos do assoalho pélvico AFA, Pad Test (teste que avalia o grau da incontinência urinária, feito com base no peso de um absorvente íntimo) e perineômetro, no início e após 10 sessões de tratamento utilizando o Método Pilates, com duração de 40 minutos. Os pesquisadores observaram que todas as pacientes obtiveram melhora da força e resistência da MAP após o tratamento e consideraram que os resultados demonstraram influência positiva do Método Pilates no tratamento para IUE em mulheres, proporcionando o fortalecimento $\mathrm{e}$ aumento da força da MAP, com efeito na redução da frequência e da quantidade da perda do conteúdo urinário.

Um aspecto negativo comum a todos os estudos citados é que mulheres com alergia ao látex (material que compõe o preservativo e luvas descartáveis) foram excluídas, sem nenhuma alternativa para poder participar em qualquer das pesquisas.

\section{CONSIDERAÇÕES FINAIS}

Os estudos encontrados sobre os efeitos do Método Pilates na funcionalidade do AP feminino e na IU apontaram resultados positivos e, em nenhum deles houve piora da IU. Nove dos dez estudos evidenciaram melhora na maioria das variáveis, exceto no estudo de Ferla et al. ${ }^{(20)}$ no qual não foi encontrada nenhuma diferença nos resultados ao comparar o grupo de sedentárias com praticantes do Método Pilates (talvez porque o grupo tenha sido composto de mulheres de 20 a 
40 anos, nulíparas, sem sobrepeso, logo, o grupo não tinha nenhuma das principais características que podem levar à disfunção do AP).

A IU pode limitar os relacionamentos pessoais e sociais das mulheres, bem como a realização das atividades físicas e diárias. Os tratamentos convencionais são normalmente invasivos, se tornando de difícil adesão e continuidade. Cabe ressaltar que o trabalho multidisciplinar de profissionais da área da saúde (Médicos Urologistas/Ginecologistas, Fisioterapeutas, Psicólogas, Nutricionistas e Profissionais de Educação Física), é de extrema importância. Embora todos os autores reconheçam a necessidade da realização de mais estudos, o MP parece ser uma alternativa adjuvante para mulheres que sofrem com as disfunções do AP (como a IU), pois, além de configurar-se como um exercício de condicionamento do corpo todo, também é um exercício que pode contribuir com a manutenção da MAP e prevenção das disfunções do AP. No campo da Educação Física, o assunto ainda é pouco discutido. Talvez por ser uma musculatura profunda, não lhe seja dada a devida importância. A funcionalidade da MAP é um tema que pode e deve ser abordado por profissionais da área do movimento, portanto, é necessário que todos tenham conhecimento e que este tema seja abordado nas aulas de anatomia, cinesiologia e biomecânica, com ênfase semelhante a qualquer outro grupo muscular.

\section{REFERÊNCIAS}

1. Moore KL, Agur AMR. Fundamentos da anatomia clínica. Rio de Janeiro: Guanabara Koogan; 2004.

2. Silva APS, Silva JS. A importância dos músculos do assoalho pélvico feminino, sob uma visão anatômica. Fisioterapia Brasil, 2003; 4(3): 205-211.

3. Palma PCR, Portugal HSP. Anatomia do assoalho pélvico. In: Palma PCR. Urofisioterapia. Aplicações clínicas das técnicas fisioterapêuticas nas disfunções miccionais e do assoalho pélvico. Campinas: Personal Link Comunicações; 2009. p. 25-37.

4. IUGA (Associação Internacional de Uroginecologia). Incontinência Urinária de Esforço: um guia para mulheres. [acesso em: 04 nov. 2018]. Disponível em: $<$ https://www.yourpelvicfloor.org/conditions/stressurinary-incontinence/>.
5. Moreno AL. Fisioterapia em uroginecologia $2^{\text {a }}$ ed. Barueri: Manole; 2009.

6. Baracho E. Fisioterapia aplicada à obstetrícia: aspectos de ginecologia e neonatologia. Rio de Janeiro: Editora Médica e Científica; 2002.

7. Kisner C, Colby LA. Exercícios terapêuticos: fundamentos e técnicas. Barueri: Manole; 2016.

8. Viktrup L, Rortveit G, Lose G. Risk of stress urinary incontinence twelve years after the first pregnancy and delivery. Obstetrical and Gynecological Survey, 2006; 108(2): 248-254.

9. Caetano AS, Tavares MCGCF, Lopes MHBM. Incontinência urinária e a prática de atividades físicas. Rev Bras Med Esporte, 2007(4): 270-274.

10. Naves PP. Avaliação da qualidade de vida em mulheres com sintomas de Incontinência Urinária de Esforço e Praticantes de Atividade Física. Revista Inspirar Movimento e Saúde, 2016; 2(37).

11. Santos CRS, Santos VLCG. Prevalência da incontinência urinária em amostra randomizada da população urbana de Pouso Alegre, Minas Gerais, Brasil. Rev. Latino-Am. Enfermagem, 2010; 18(5): [8 telas].

12. Siler B. O corpo Pilates: um guia completo para fortalecimento, alongamento e tonificação sem o uso de máquinas. São Paulo: Summus; 2008.

13. Aparício E, Pérez J. O autêntico Método Pilates: a arte do controle. São Paulo: Editora Planeta do Brasil; 2005.

14. Muscolino, JE, Cipriani S. Pilates and "Powerhouse" I. Journal of Bodywork and Movement Therapies, 2004; (8) $1: 15-24$.

15. Cintas J. A ciência do pilates: Como otimizar suas aulas pela biomecânica. São Paulo: Sarvier; 2018.

16. Isacowitz, R; Clippinger, K. Anatomia do Pilates. Barueri, São Paulo: Manole, 2013.

17. Andreazza EI, Serra E. A influência do Método Pilates no fortalecimento do assoalho pélvico. Disponível em: http://activepilates.com.br/producoes/A-INFLUÊNCIADO-MÉTODO-PILATES-NO-FORTALECIMENTODO-ASSOALHO.pdf Acesso em: 19 Jul 2019.

18. Culligan PJ, Scherer J, Dyer K, Priestley J.L, White GG, Delvecchio D, Vangeli M. A randomized clinical trial comparing pelvic floor muscle training to a Pilates exercise program for improving pelvic muscle strength. International Urogynecology Journal, 2010; 21(4): 401-408.

19. Diniz MF, Vasconcelos TB, Pires JLVR, Nogueira MM, Arcanjo GN. Assessment of the strength of the pelvic floor musculature in women who practice Mat Pilates. Man. Ther., Posturology Rehabil. J., 2014; 12: 126-130. 
20. Ferla L, Paiva LL, Darki C, Vieira A. Comparison of the functionality of pelvic floor muscles in women who practice the Pilates method and sedentary women: a pilot study. International Urogynecology Journal, 2015; 27(1): 123-128.

21. Laycock J, Jerwood D. Pelvic floor assessment; the PERFECT scheme. Physiotherapy, 2001; 87(12): 631-642.

22. Pereira AJ, Spiller MG, Garcia EP, Correa RG. Influência do Método Pilates na incontinência urinária de urgência dupla. Revista Hórus, 2016; 11(1): 68-80.

23. Tamanini JTN, Dambros M, D'Ancona CAL, Palma PCR, Netto Jr. NR. Validação para o português do International Consultation on Incontinence Questionnaire - Short Form (ICIQ-SF). Revista Saúde Pública, 2004; 38(3):438444.

24. Bertoldi J, Medeiros AM, Goulart SO. The method pilates effects on pelvic floor of climacteric women: a case of study. Cinergis, 2015; 16(4): 255-260.

25. Silva Filho CR, Baracat EC, Conterno LO, Haidar MA, Ferraz MB. Climacteric symptoms and quality of life: validity of women's health questionnaire. Rev. Saúde Pública, 2005; 39(3): 333-339.

26. Souza LM, Pegorare ABGS, Christofoletti G, Barbosa SRM. Influence of a protocol of Pilates exercises on the contractility of the pelvic floor muscles of noninstitutionalized elderly persons. Rev. bras. geriatr. gerontol., 2017; 20(4): 484-492.

27. Torelli L, Di Bella ZIKJ, Rodrigues CA, Stüpp A, Girão MJBC, Sartori MGF. Effectiveness of adding voluntary pelvic floor muscle contraction to a Pilates exercise program: an assessor-masked randomized controlled trial. International Urogynecology Journal, 2016; 27(11): 1743-1752.
28. Schrader EP, Frare JC, Comparin KA, Diamante C, Araújo BG, Danielli C, Murbach LD. Eficácia do método Pilates e do biofeedback manométrico em mulheres na menopausa com incontinência urinária. Sêmina: Ciências Biológicas e da Saúde, 2017; 38(1): 61-78.

29. Coelho KC, Silva DC, Barbosa TFC, Witting DS, Palácio SG, Perin O. A eficácia do Método Pilates no tratamento de mulheres com incontinência urinária de esforço. Revista Científica JOPEF, 2018; 25(01): 5-15.

\section{Como citar este artigo:}

Couto APJP, Toigo AM. Os efeitos do método Pilates na funcionalidade do assoalho pélvico feminino e na incontinência urinária: uma revisão sistemática. Rev. Aten. Saúde. 2019; 17(62): 109-124. 